\title{
A hybrid approach to compensate non-linear loads in electrical power systems
}

\author{
Jesús R. Vázquez, Juan L. Flores, Patricio Salmerón, Salvador P. Litrán \\ Department of Electrical Engineering \\ Escuela Politécnica Superior, Universidad de Huelva \\ Ctra. de Palos de la Frontera s/n 21819, Palos de la Frontera. Huelva (Spain) \\ phone:+34 959017579 , fax:+34959017304 \\ e-mail: vazquez@uhu.es,juan.flores@die.uhu.es, patricio@uhu.es, salvador@uhu.es
}

\begin{abstract}
In this paper, a hybrid passive-active power filter is proposed to compensate the non-linear loads in electrical power systems. The main compensation target is to mitigate the load current harmonics. An active power filter can be used to eliminate the load current harmonics, but it is a high cost solution. The use of passive filters are a more economical solution, but the main problem is that these filters cause resonance currents in the system. In this case, two shunt passive LC filters are designed to eliminate the more significant load harmonics. An active power filter, in series with them, is used to improve the filtering characteristics. Besides, it avoids the resonance between the source impedance and the passive filter impedance. This hybrid shunt conditioner is more effective than only a shunt passive filter, and it is a cheaper solution than a shunt active power line conditioner alone. A practical case is presented to check the proposed hybrid conditioner: the compensation of a three-phase diode rectifier.
\end{abstract}

Key words: Compensation, Harmonics, Power Quality, Hybrid Filter, Active Power Filter

\section{Introduction}

In the last years, there has been an increase of non-linear loads as electronic devices in the electric power distribution networks. The current harmonics consumed by these loads flowing through the line impedances cause distorted voltages, and the significant harmonics are extended to the rest of the network. There are some possibilities to restore the power quality in power systems, [1,2]. So, when the current harmonics are known, the passive filters resonant with the main harmonic frequencies are a usual solution. One of its advantages is the lower cost of the filter. However, there are some disadvantages, mainly that the filter does not eliminate another harmonics, and resonance problems with the system impedances can appear. Recent development of signal processing and power converters allows to use the power active filters (APFs) to improve the electrical power quality, $[3,4]$. The main disadvantage is the price.

It is possible to combine passive and active filters to get both advantages. Many proposals have been realized, [511]. The objective of this work is to design a shunt hybrid passive-active filter to eliminate the load harmonics. The passive filter is connected in parallel with the load. It includes some LC branches that offer null impedance to the main current harmonics. The APF is connected in series with the passive filter. The scheme of the compensated system is presented in figure 1 .

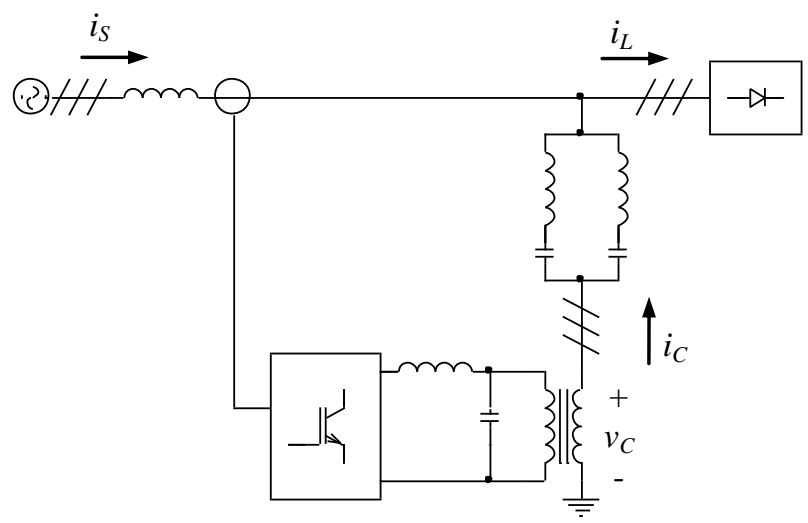

Figure 1. Three-phase system compensated with a hybrid filter

Fig. 1 shows a three-phase diagram of proposed shunt hybrid filter. Two passive LC branches are connected in series with an active filter. If the active filter is not connected, the compensation current, $i_{C}$, mitigates the main harmonics of load current, $i_{L}$, and it is possible that a series resonance between the source impedance and the LC branches will appear. So, the source current, $i_{S}$, will include certain harmonics and the distortion is not completely reduced. If the active filter is included, an appropriate control allows to modify the impedance of shunt compensator at resonance frequencies, and the problem can be avoided.

To check the hybrid filter performance, it has been developed a simulation platform with Matlab/Simulink software, helped by the System Power blockset. A threephase diode rectifier has been compensated by an hybrid filter consisting of two-branch shunt passive filter in series with an active power filter.

\section{Hybrid filter design}

The filter hybrid design depends on the load to be compensated. It must contain some passive LC branches, one for each important load current harmonic to be removed from the source current. In the case of many typical loads, it is usually enough to employ one, two or three branches for the main harmonics. By three-phase systems it is possible to reduce or eliminate the $3^{\text {rd }}$ harmonic order and its multiples by suitable connections of the transformers supplying the power to the load.

Therefore it is usual to include LC branches tuned for the $5^{\text {th }}$ and $7^{\text {th }}$ harmonic order. 
The values of the $L_{n}$ and $C_{n}$ parameters of a branch tuned for an " $n$ " order harmonic must satisfy the equation (1).

$$
\omega_{n}=2 \pi f n=\frac{1}{\sqrt{L_{n} C_{n}}}
$$

where $\mathrm{f}$ corresponds to the fundamental frequency, that was taken as $50 \mathrm{~Hz}$ in this work.

The active filter connected in series with the passive branches can be seen as a controlled voltage source. Different strategies are possible to control this compensation voltage. In single-phase or balanced threephase systems, a voltage $\boldsymbol{v}_{\boldsymbol{C}}$ proportional to the source harmonic current $\boldsymbol{I}_{\boldsymbol{S H}}$ permits to modify the impedance of the shunt compensator, and the passive filter performance is improved. Figure $2 \mathrm{a}$ shows the equivalent single-phase circuit for the compensated system. The non-linear load is modelled by a current source. For a determined harmonic of order $\mathrm{H}$, the equivalent circuit is shown in figure $2 \mathrm{~b}$.

From the circuit $2 b$, it is possible to obtain the source harmonic current, equation 2 .

$$
I_{S H}=\frac{Z_{F}}{\left(Z_{S}+Z_{F}+K\right)} I_{L H}+\frac{1}{\left(Z_{S}+Z_{F}+K\right)} V_{S H}
$$

Ideally, the source harmonic currents will be null if $\mathrm{K}=\infty$. If $K \gg\left(Z_{S}+Z_{F}\right)$, this strategy allows to reduce series resonance between the source and the filter. It avoids that the passive filter receives the harmonic current of the rest of the system. In the practical case simulated in this work a value of $K=2$ is used.

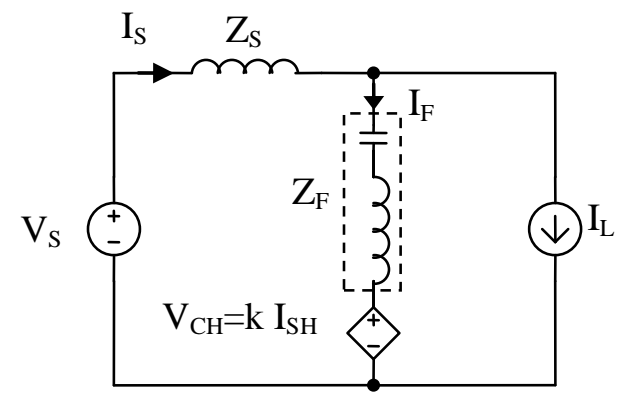

a)

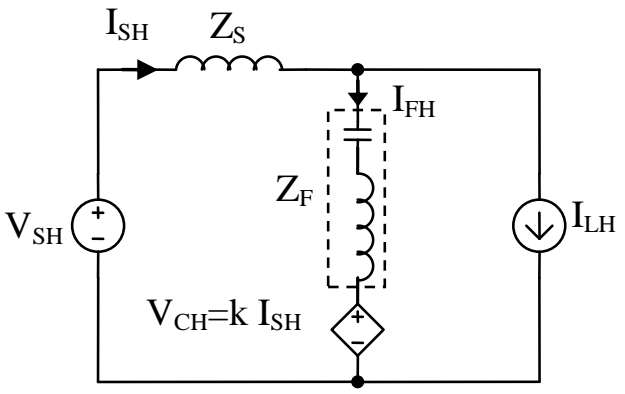

b)

Figure 2. a) Equivalent circuit of the compensated system, b) Equivalent circuit for harmonic of order $\mathrm{H}$

The output voltage of active power converter includes no desired high frequency harmonics caused by the switching devices operation. It is necessary to carry out a passive filtering. The series connection with the LC branches is carried out by means of a transformer. This allows to have low voltage values at the dc side of the inverter. Figure 3 shows the three-phase circuit under study. The system has been developed in Simulink to simulate the practical case presented in the next section.

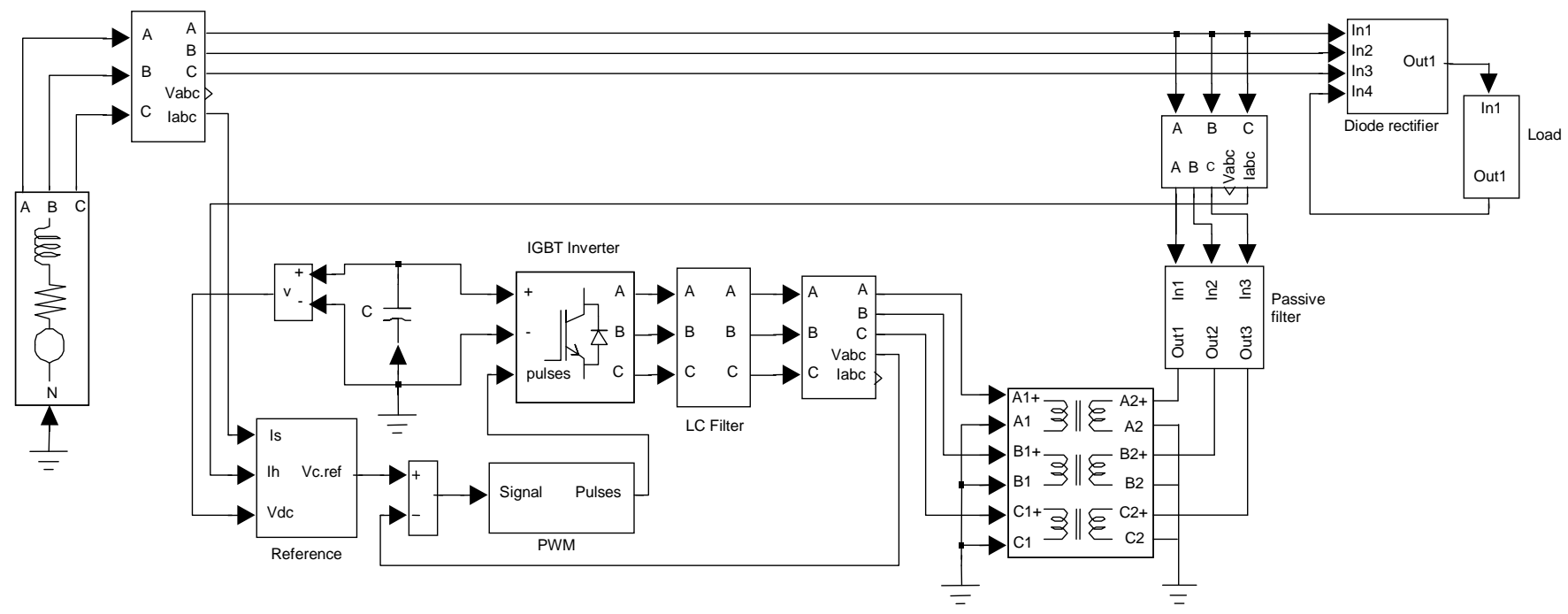

Figure 3. Block scheme of a three-phase system compensated by the proposed hybrid filter. 


\section{A practical case}

\subsection{System description}

In this work, a three-phase diode rectifier has been compensated to check the hybrid filter performance. Figure 4 shows a scheme of the load. It presents mainly $5^{\text {th }}$ and $7^{\text {th }}$ order harmonics, figure 5 .

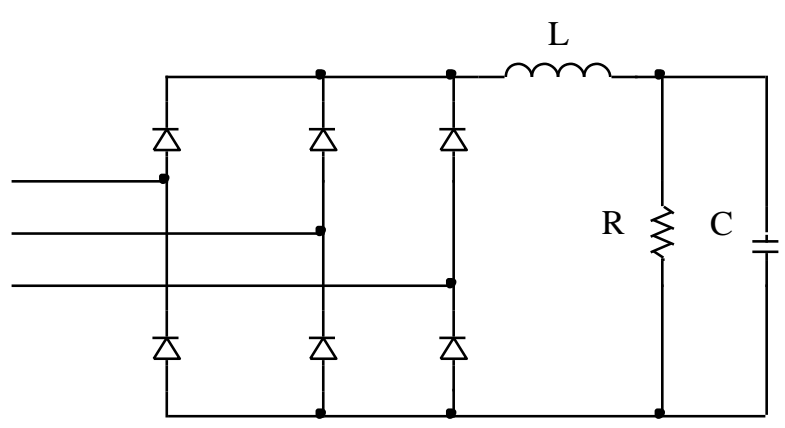

Figure 4. Scheme of a three-phase diode rectifier

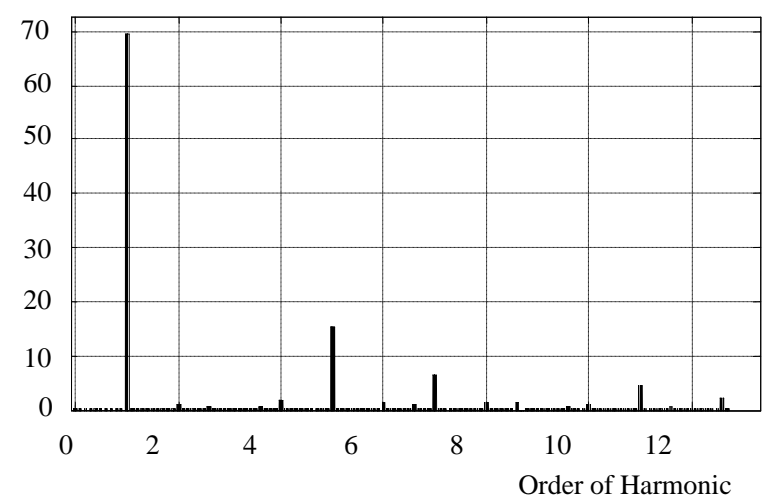

Figure 5. Peak Magnitude of Harmonic Spectrum of phase-1 load current

The source voltage is $400 \mathrm{~V}$ phase to phase, $50 \mathrm{~Hz}$, and it includes a small amount of harmonics $4^{\text {th }}$ and $6^{\text {th }}(2 \%$ of the fundamental) in order to show the effects of the passive filter resonance without the series active power filter.

Table I shows the compensated system main parameters values. It includes the source impedance parameters, $\mathrm{L}$ and $\mathrm{C}$ values for both passive branches used, and the power rate needed for the active power filter

As it can be observed in Table I, the APF power used is very low, and consequently the costs of the designed filter are also reduced.

The system has been simulated without and with the active power filter to compare the performance of passive and hybrid filter.
Table I. System parameters in a practical case: a threephase rectifier with a parallel passive and active filter

\begin{tabular}{|c|c|}
\hline $\begin{array}{l}\text { Power } \\
\text { circuit } \\
\text { source }\end{array}$ & $\begin{array}{l}\text { Phase-to-Phase voltage }=400 \mathrm{~V}_{\mathrm{RMS}} \\
\text { Frecuency }=50 \mathrm{~Hz} \\
4 \text { th harmonic magnitude }=2 \% \text { of fundamental } \\
6 \text { th harmonic magnitude }=2 \% \text { of fundamental } \\
\text { Source resistance }=0.002 \Omega \\
\text { Source inductance }=2 \mathrm{mH}\end{array}$ \\
\hline Load & $\begin{array}{l}\text { Apparent Power }=45 \mathrm{kVA} \\
\text { Load dc side resistance } \mathrm{R}=6 \Omega \\
\text { Load dc side inductance } \mathrm{L}=0,4 \mathrm{mH} \\
\text { Load dc side capacitor } \mathrm{C}=1 \mu \mathrm{F}\end{array}$ \\
\hline $\begin{array}{l}\text { Passive } \\
\text { Filter }\end{array}$ & $\begin{array}{l}5 \text { th order branch inductance } \mathrm{L}_{5}=4,05 \mathrm{mH} \\
5 \text { th order branch capacitor } \mathrm{C}_{5}=100 \mu \mathrm{F} \\
7 \text { th order branch inductance } \mathrm{L}_{7}=2,07 \mathrm{mH} \\
7 \text { th order branch capacitor } \mathrm{C}_{7}=100 \mu \mathrm{F}\end{array}$ \\
\hline $\begin{array}{l}\text { Active } \\
\text { Filter }\end{array}$ & Apparent Power $=0,24 \mathrm{kVA}$ \\
\hline
\end{tabular}

\subsection{Passive filter compensation}

In this case, only the LC passive branches are connected in parallel with the load. Figures $6 a$ and $6 \mathrm{~b}$ show compensation and source current spectrums. There is series resonance between the source impedance and each LC branch. The source current obtained is not exactly sinusoidal, it includes $4^{\text {th }}$ and $6^{\text {th }}$ order harmonics.

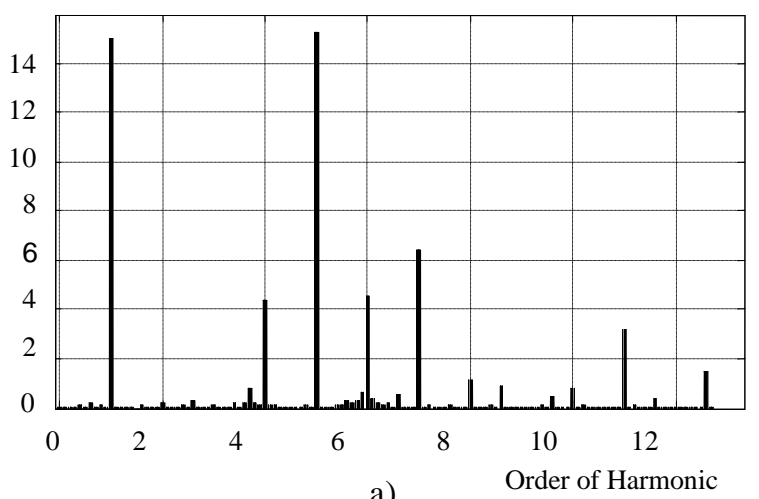

a)

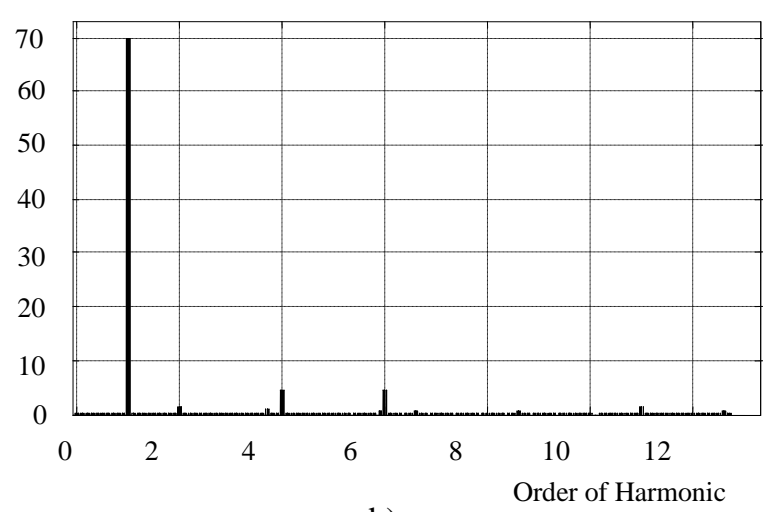

b)

Figure 6. Harmonic Spectrum of phase-1 currents with passive filter, a) filter current, b) source current 
Figure 7 presents the load, the filter and the source current waveforms of phase-1. With the passive filter connected, the total harmonic distortion is reduced, but the resonance does not allow a greater reduction. Table II shows the THD values of source current before and after the compensation.

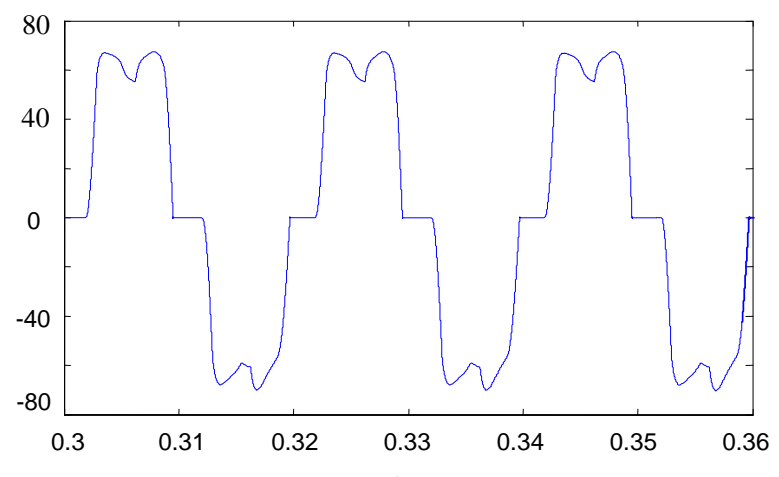

a)

Time, $s$

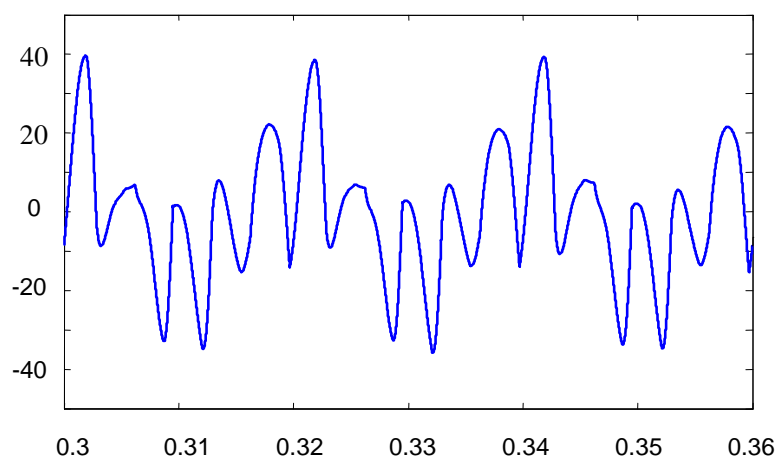

b)

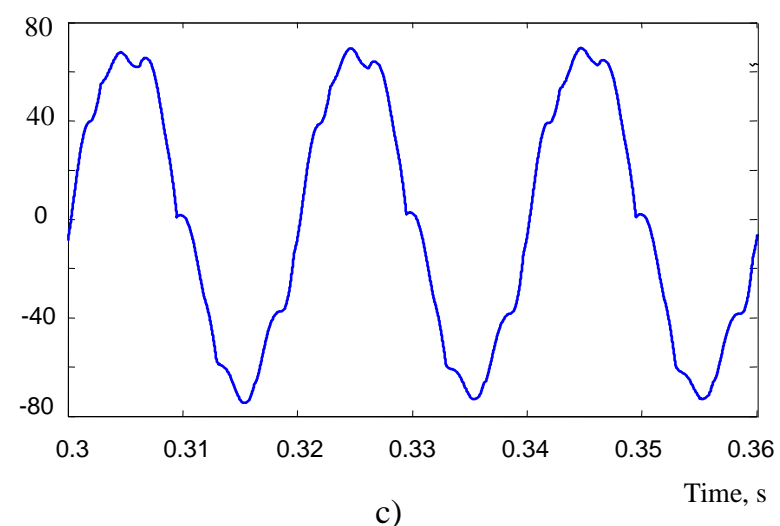

c)

Figure 7. Phase-1 currents at compensated system, a) load current, b) compensation current, c) source current

Table II. Source current THD values, before and after the compensation

\begin{tabular}{c|c}
\hline Source Current & THD \\
\hline $\begin{array}{c}\text { Before the } \\
\text { compensation }\end{array}$ & $25,49 \%$ \\
\hline $\begin{array}{c}\text { After the } \\
\text { compensation }\end{array}$ & $9,13 \%$ \\
\hline
\end{tabular}

\subsection{Hybrid filter compensation}

When the active power filter is connected in series with the passive branches, the resonance is damped. The source and compensation currents spectrums don't include the $4^{\text {th }}$ and $6^{\text {th }}$ order harmonics, figure 8 .

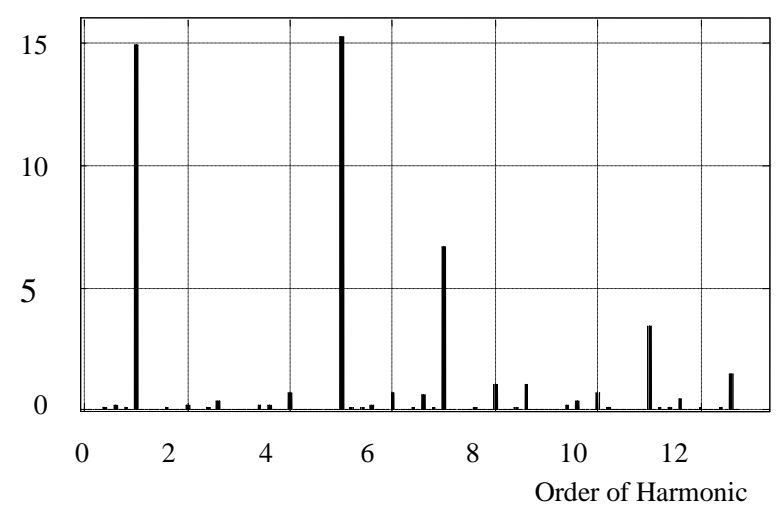

a)

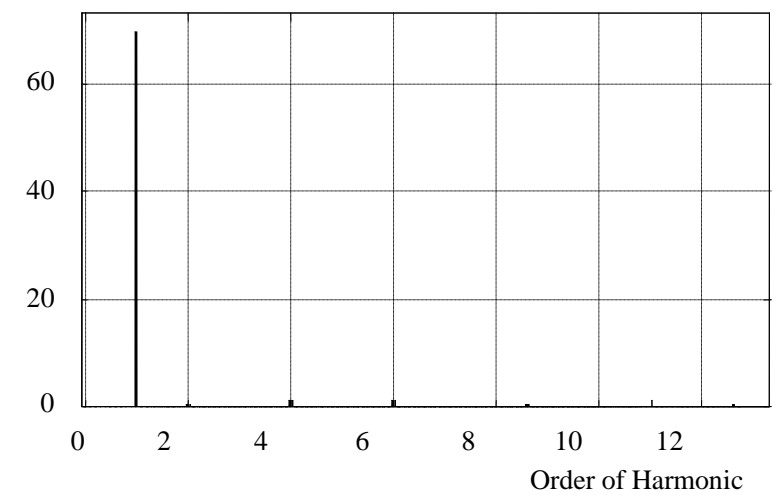

b)

Figure 8. Peak Magnitude Spectrum of phase-1 currents with hybrid filter, a) filter current, b) source current

The hybrid filter allows to compensate the load harmonics, and the source current becomes sinusoidal. Figure 9 presents the load, the filter and source current waveforms of one phase in the compensated system. Figure 10 shows all-phases load and source currents.

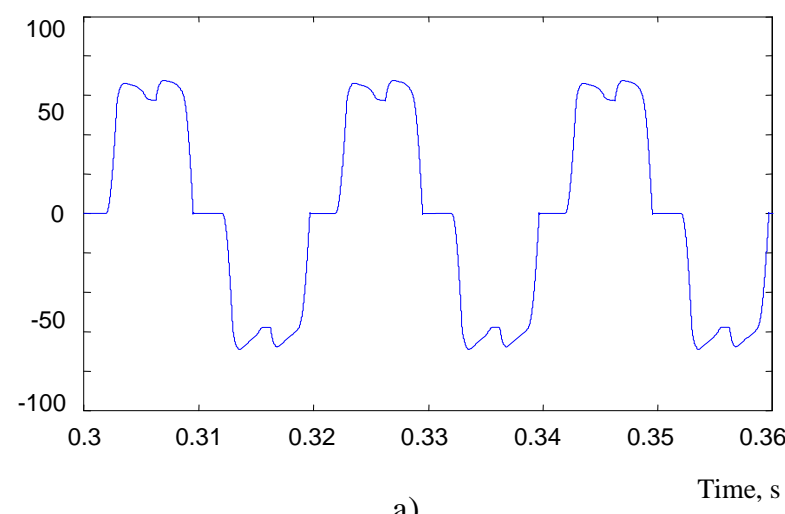

a) 

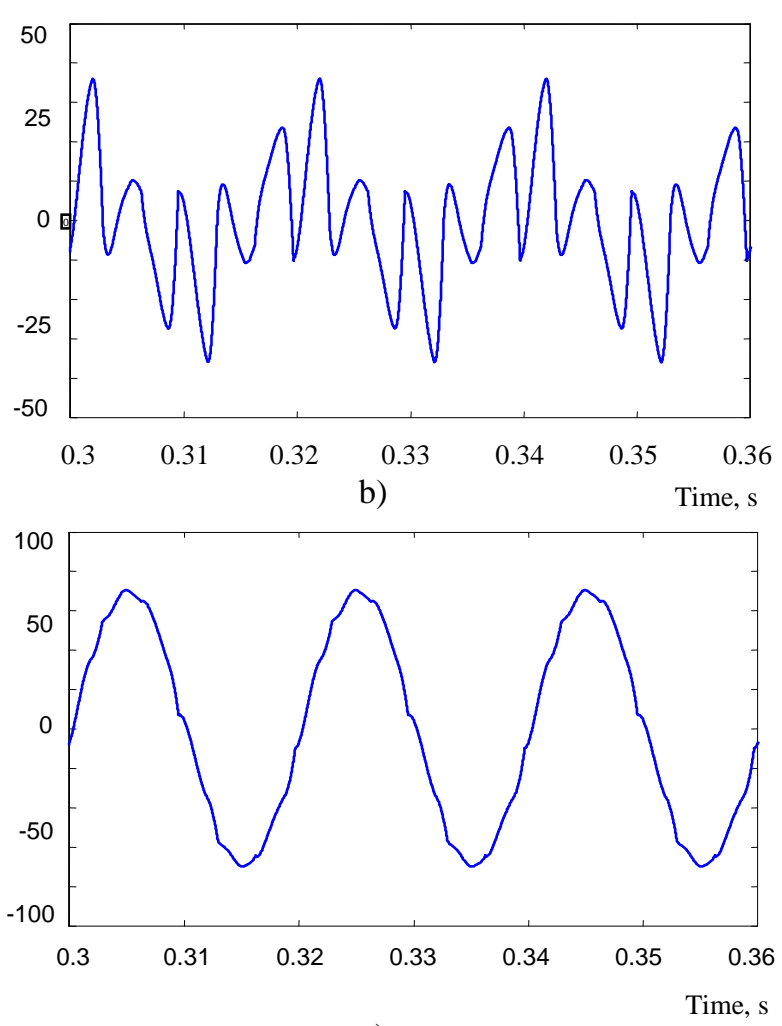

c)

Figure 9. Phase-1 currents at compensated system, a) load current, b) compensation current, c) source current

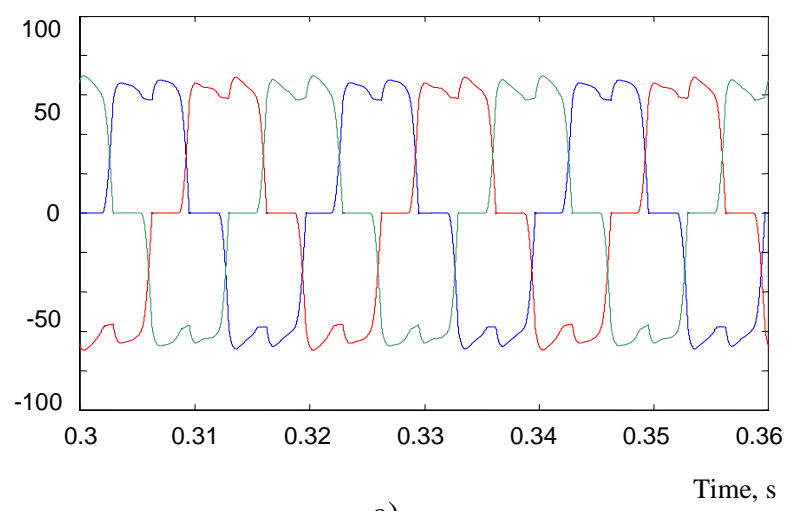

a)

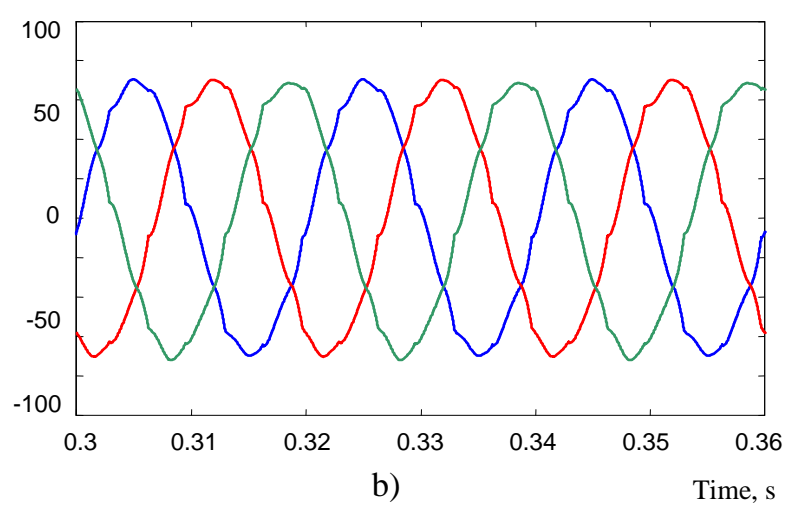

Figure 10. Three-Phase results, a) load currents, b) source currents
The source current distortion values before and after compensation are shown in table III. The Total Harmonic Distortion is reduced from $27 \%$ to $3 \%$ using an ideal inverter in the APF to follow the reference compensation current.

Table III. Source current THD values, before and after the compensation

\begin{tabular}{c|c}
\hline Source Current & THD \\
\hline $\begin{array}{c}\text { Before the } \\
\text { compensation }\end{array}$ & $25,83 \%$ \\
\hline $\begin{array}{c}\text { After the } \\
\text { compensation }\end{array}$ & $3,2 \%$ \\
\hline
\end{tabular}

\section{Conclusions}

A shunt hybrid power filter has been proposed to compensate the load current harmonics. While a shunt passive filter eliminates the main load harmonics, an active power filter, in series with it, avoids the resonance problems and improves the global filter performance. The solution is effective and more economical than an shunt active power filter, because it is sufficient an active power filter of a low VA ratio.

A practical case has been presented to check the filter performance, the compensation of a three-phase diode rectifier. Thus, the results have shown that the source current distortion is reduced from $26 \%$ to $3 \%$ in the compensated system.

\section{Acknowledgement}

This work is within the project "Harmonic Distortion Compensation in Electrical Installations using Different Configurations of Active Power Filters." DPI200301336, financed by the CICYT (Ministerio de Ciencia y Tecnología, Spain).

\section{References}

[1] Akagi, H. "New trends in active filters for power conditioning", Industry Applications, IEEE Transactions on, Vol. 32, Issue 6, Pages 1312-1322, Nov.-Dec. 1996.

[2] F. Z. Peng and D. J. Adams, "Harmonics sources and filtering approaches," in Proc. Industry Aplications Conference, October 1999, Vol, 1, pp. 448-455.

[3] W. M. Grady, M. J. Samotyj, A. H. Noyola. "Survey of Active Power Line Conditioning Methodologies". IEEE Transactions on Power Delivery, Vol. 5, No. 3, Julio 1990, pp. 1536-1542.

[4] P. Salmerón, J.C. Montaño, J. R. Vázquez, J. Prieto and A. Pérez, "Compensation in Nonsinusoidal, Unbalanced Three-Phase, Four-Wire Systems With Active PowerLine Conditioner", IEEE Trans. On Power Delivery Vol.19, No. 4 October-2004, pp. 1968-1974. 
[5] H. Fujita, T. Yamasaki, H. Akagi, "A hybrid active power filter for damping of harmonic resonance in industrial power systems", IEEE Transactions on Power Electronics, Vol. 15, No. 2 , pages 215 - 222, March 2000.

[6] B-R. Lin, B-R. Yang, H-R. Tsai, "Analysis and operation of hybrid active filter for harmonic elimination", Electric Power Systems Research 62, Elsevier Science B.V., pages $191-200,2002$.

[7] D. Rivas, L. Morán, J. Dixon, J. Espinoza, "A simple control scheme for hybrid active power filter", Generation, Transmission and Distribution, IEE Proceedings, Vol. 149, Issue 4, pgs 485 - 490, July 2002.

[8] H.L. Jou, J.C. Wu, K.D. Wu, "Parallel operation of passive power filter and hybrid power filter for harmonic suppression", Generation, Transmission and Distribution, IEE Proceedings, Vol. 148, Issue 1, Pages 8 - 14, January 2001.
[9] Y. Wang, Z. Wang, J. Yang, J. Liu, Y. Duan, Z. Fu, Y. Hua, "A new hybrid parallel active filter", Power Electronics Specialist, PESC'03, IEEE 34th Annual Conference on, Vol. 3, Pages 1049 - 1054, June 2003.

[10] D. Rivas, L. Morán, J. Dixon, J. Espinoza, "Improving passive filter compensation performance with active techniques", Industrial Electronics, IEEE Transactions on, Vol. 50, Issue 1, Pages 161 - 170, February 2003.

[11] M. Routimo, M. Salo, H. Tuusa, "Wideband harmonic compensation with a voltage-source hybrid active power filter", Applied Power Electronics Conference and Exposition, APEC'04, Nineteenth Annual IEEE, Vol. 1, Pages 191 - 196, 2004. 